PEREIRA, Caio Mario da Silva. Instituições de Direito Civil. Vol. I, 14. ed., Forense, 1993.

PERLINGIERE, Pietro Perlingiere. Il Diritto Civile nella Legalità Constituzionale. Nápoles: Edizione Scientifiche Italiane, 1991.

PONTES DE MIRANDA, J. Tratado de Direito Privado. T. I, Rio de Janeiro: Borsoi, 1954.

RAPOSO, Mário. "Procriação Assistida - As. pectos Éticos e Jurídicos". In Direito da Saúde e Bioética. Lisboa: Lex, 1991.

REALE, Miguel. Teoria Tridimensional do Direito. São Paulo: Saraiva, 1994.

. Verdade e Conjetura. São Paulo: Nova Fronteira, 1983.

. Fundamentos do Direito. São Paulo: Revista dos Tribunais, 1998.

. Fontes e Modelos do Direito - para um novo paradigma hermenêutico. São Paulo: Saraiva, 1994
SESSARIEGO, Carlos Fernandez. "Protección a la persona humana". In Revista Ajuris $n^{0}$ 56. Porto Alegre, 1992.

TABORDA, Maren. A Publicização da noção de pessoa jurídica como fator de construção da dogmática do "Estado de Direito". Porto Ale. gre, 2000, datilografado, inédito.

VIDAL, Marciano. "Clonagem: Realidade Técnica e Avaliação Ética”. In Ética e Engenharia Genética, Concilium/275 - 1998-2. Rio de Janeiro: Vozes, 1998.

VIOLA, Francesco, e ZACCARIA, G. Diritto e Interpretazione - Lineamenti di teoria ermeneutica del diritto. Roma: Laterza, 1999.

ZACCARIA, Giuseppe. "Sul Concetto di Positività del Diritto". In Diritto Positivo e Positività del Diritto (org. G. Zaccaria). Milão: Giappichelli, 1989.

\section{Algumas contribuições da ciência histórica à tarefa do historiador do Direito}

\author{
Launa Beck Pavela
}

Mestranda em Direito pela UFRGS.

El historiador no ofrece modelos, sino que señala el sentido de la línea. Digamos que disuelve el absolutismo del presente relativizándolo gracias a su inserción em la línea, pero dotándole así también de uma conciencia más aguda de la propia dirección, de una dirección que no se encuentra certeramente trazada por um incesante movimiento evolutivo bajo el signo de un constante progreso, sino que está circunstanciadamente trenzada com el recurso de la única riqueza disponible para la experiencia humana, la vida enteramente vivida, en exposición completa com todo su patrimonia de valores y desvalores" 1 (PAOLO GROSSI, Professor de História do Direito da Universidade de Florença, Itália)

\section{SUMÁRIO:}

Introdução.

I- Notas sobre a ciência histórica.

II - Algumas contribuições da ciência histórica à tarefa do historiador do Direito.

Conclusão.

Bibliografia.

\section{Introdução}

herança positivista legou à teoria do A direito a identificação entre este e a lei, afastando-o da consideração de quaisquer elementos que não fossem estritamente jurídicos. Paralelamente, a vertente filosófica do jusnaturalismo racionalista contribuiu para a preponderância da concepção de um direito a-histórico, eterno, imutável. ${ }^{2}$

Há algumas décadas, contudo, têm surgido escritos sobre História do Direito, revelando a preocupação de traçar a evolu. ção do fenômeno jurídico e da forma de pensar o direito, suas continuidades e

1. PAOLO GROSSI, "El punto y la línea (historia del derechoy derecho positivo en la formación del jurista del nostro tiempo)", discurso proferido por ocasião do recebimento do título de doutor honoris causa na Universidade de Sevilha, 1998, p. 29.

2. A elaboração dos códigos civis, nos séculos XVIII e XIX, corresponderia ao ápice de uma evolução que se vinha decorrespondera ao ápice do un lineando desde os romanos. Trata-se do equivalente juridico da noçáa de progresso historico (Conforme LE GOFF, Historia e Memóra, p. 14). PAOLO GROSSl aponta os fabres que explicam o tenomeno que ousamos chamar de
"deshistoricização" do direito (ob. cit., p.20). 
descontinuidades. Exemplos dessa tendência que busca resgatar a importância e a indispensabilidade da "perspectiva histórica" para a compreensão do jurídico são, dentre inúmeras outras, as obras de FRANZ WIEACKER, na Alemanha; BARTOLOMÉ CLAVERO, na Espanha; PAOLO GROSSI, na Itália; CABRAL DE MONCADA, MÁRIO JÚLIO DE ALMEIDA COSTA, NUNO ESPINOSA GOMES DA SILVA e ANTÔNIO MANUEL HESPANHA, em Portugal; MIGUEL REALE e NELSON SALDANHA, no Brasil.

$O$ presente estudo visa, destarte, apontar algumas questões para uma análise do estatuto epistemológico da disciplina da História do Direito. Quais seus limites, seu objeto, sua especificidade? Qual a tarefa do historiador do direito? É possível a elaboração de um instrumental teórico para análise do fenômeno jurídico no seio da História do Direito? Qual a sua contribuição, ao lado da Filosofia do Direito, para repensar a teoria do Direito? ${ }^{3}$ E qual a especificidade da História do Direito, que legitima sua caracterização como ramo da História (se for possível).

Não temos a pretensão de solucionar as inquietações indicadas, mas apenas de apontar alguns caminhos. É na historiografia que encontraremos apoio para tais reflexões. Assim, na primeira parte do trabalho em epígrafe, tratar-se-á de algu-

mas questões concernentes ao estatuto científico da História, seu objeto e sua relação com o tempo, à luz da contribuição de duas das principais escolas da história analítica/estrutural: marxismo e escola dos annales.

Evidentemente, tais notas, feitas na condição de observateur da ciência histórica, não pretendem esgotar a temática, antes dirigem seu olhar aos aspectos que podem ser relacionados com a disciplina da História do Direito - o que já revela a parcialidade e estreiteza da análise.

A partir desses pressupostos, intentaremos, na segunda parte, identificar algumas contribuições da História à História do Direito, tendo em vista as questões acima referidas, ou seja, a investigação sobre a natureza da História do Direito. ${ }^{4}$ Não são certamente as únicas "pontes" entre a História e a História do Direito; cuida-se tãosomente dos primeiros passos num terreno ainda pouco explorado.

\section{I - Notas sobre a ciência \\ histórica}

Considerando que o norte do presente estudo reside na reflexão sobre a Histó ria do Direito, e não sobre o estatuto epistemológico da História propriamente dita, iniciamos a abordagem da cientificidade na História com a seguinte passagem de HOBSBAWN:

3. Tais inquietaçães orientam nosso estudo, ainda que não se tenha a pretensão de solucioná-las num trabalho de dimensões limitadas como o que ora se propõe.

4. É também a insatisfação com o indesejável distanciamento - historicamente explicável, diga-se de passagem - que o Direito mantém em relação às demais ciências sociais, que inspira o presente estudo.

Revista da Faculdade de Direito da UFRGS, v. 18, 2000
"De fato, a insistência dos histo riadores (...) em procedimentos estritamente científicos, onde cada declaração é acompanhada de provas, fontes de referências e citações, é às vezes pedante e trivial, principalmente agora que isso não participa mais de uma fé na possibilidade de uma verdade científica definitiva, positivista, que lhe conferia uma certa grandeza simplória. No entanto, os procedimentos do tribunal de justiça, que insistem na supremacia da evidência com a mesma força que os pesquisadores históricos, e muitas vezes quase da mesma maneira, demonstram que a diferença entre fato histórico e falsidade não é ideológica. (...) Quando uma pessoa inocente é julgada por assassinato, e deseja provar sua inocência, aquilo de que se necessita não são as técnicas do teórico pós-moderno, mas do antiquado historiador."

O autor, em sua crítica às vertentes da denominada pós-modernidade, aproxima a busca da verdade na história àquela intentada pelos operadores jurídicos nos

tribunais. A dupla história-ficção, que vem suscitando discussões em torno do estatuto cognitivo historiográfico, seria oposta à aproximação história-direito, ${ }^{6}$ como reação do paradigma racional científico às críticas pós-modernas.?

Assim, visualiza-se o que HOBSBAWN aponta ser o fundamento da ciência histórica: a supremacia da evidência, a busca da veracidade, que permanece sendo traço distintivo entre a história e as produções puramente ficcionais.

A modernização da ciência histórica, iniciada na segunda metade do séc. XVIII, tem como um de seus princípios básicos a racionalidade do método como estratégia cognitiva no trato da experiência passada. ${ }^{8} \mathrm{O}$ método racional científico aplicado à História reflete-se, além da supremacia da evidência, na tentativa de elaboração de um instrumental teórico apto a investigar a realidade social. Busca-se a ruptura com o senso comum, ou saber ideológico, ${ }^{9}$ que elaboram explicações simples,

5. HOBSBAWN, Não basta a história de identidade, p. 287. Também PATRICK NERHOT identifica o método histórico, em sua

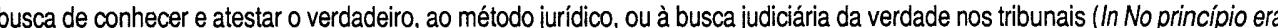
o Direito..., p. 91).

6. Outro ponto comum seria o fato de o discurso de ambas ser, via de regra, fator de legitimação dos que estão no poder (PETERSEN, 0 conhecimento histórico na atualidade, p. 213). A relaçãa entre direito e poder é particularmente evidenciada, não só pelo caráter exclusivamente estatal da produção da fonte jurídica (lei), mas também pelo fato de ser a composição de um dos três poderes da República inteiramente feita por egressos das faculdades de direito. Segundo RÜSEN, orientar é tarefa da historia (Narratividade..., p. 80) - outro traço comum entre os dois discursos, em nosso entender.

7. ROUANET identifica três vertentes da crítica ao pensamento iluminista: a primeira seria encabeçada por ADORNO e HORKHEIMER a segunda por FOUCAULT, e a terceira pelos pós-estruturalistas ou pós-modernos ("Razões do neo-iluminismo". In A criaçấo histórica. Cornelius Castoriadis e outros, p. 12). Também sobre a pós-modernidade e giro lingǘstico na história: RÜSEN, J., $A$ História entre a Modernidade e a Pós-modernidade; LACERDA, Sônia História narrativa e imaginacão histórica; Céza TEMISTOCLES, Sob o firmamento da história: 0 "mito" do texto como representaçäo objetiva do passado.

8. RÜSEN, Narratividade e Objetividade..., p. 81; CÉZAR, cit., p. 167.

9. BRAUNSTEIN, "Cómo se constituye una ciencia?", p. 11. BACHELARD examina a formação do conhecimento científico em termos de obstáculos, que seriam causas de estagnação, de inércia do ato de conhecer ( $A$ formação do espirito cientifico, pp. 1718). O primeiro obstáculo seria a opinião, experiência primeira, expressão do senso comum, que se forma antes da crítica (Ob. cit., pp. 18-19). 
confundindo o real com o aparente. ${ }^{10} \mathrm{Como}$ as demais ciências sociais, a História elabo. ra códigos de leitura do real (conceitos e relações entre conceitos) com o intuito de conhecer e interpretar a realidade social. Ao romper com o senso comum da memória coletiva, ${ }^{11}$ elabora abstrações, "categorias perceptivas". ${ }^{12}$

No plano historiográfico, consoante BRAUNSTEIN, o materialismo histórico constitui um referencial de elaboração teórica para compreensão da realidade, elegendo como conceito-chave o "modo de produção", enquanto forma de organização do trabalho humano. Em torno dele articulam-se outros lugares teóricos assinalados por MARX ${ }^{13}$ como infra-estrutura econômica, supraestrutura jurídico-política, ideologia, processo de sujeitação, luta de classes como constante na história, ${ }^{14}$ etc.

Outra importante matriz historiográfica, ao lado do marxismo, foi a escola dos Annales. ${ }^{15}$

LUCIEN FEBVRE, um de seus fundadores, ensina que a história não é mero exercício de erudição, mas uma "explicação do homem e do social a partir dessa coordenada preciosa, sutil e complexa - o tempo...". ${ }^{16}$ MARC BLOCH acrescenta que não é o passado em si o objeto da história mas a relação dos homens no tempo ${ }^{17} \mathrm{~A}$ relação com o tempo consistiria na especificidade do conhecimento histórico, seu traço distintivo das demais ciências sociais.

É significativa, a respeito do tempo, a reflexão de FERNAND BRAUDEL. ${ }^{18}$ Opondo-se ao tempo curto, instantâneo, da história política tradicional, événémentielle, propõe três dimensões da temporalidade, a serem utilizadas pelos historiadores em suas análises do real. A primeira seria a dimensão temporal geográfica, quase imóvel, esfera das relações do homem com o meio. A segunda seria a história lenta, das civiliza ções, sociedades, Estados, economias. A terceira, concernente à história tradicional seria a dimensão do indivíduo, as oscilações breves e rápidas, "agitações de superfície". ${ }^{19}$ Insurge-se contra a imposição de um só ritmo (o ritmo ágil da conjuntura econômica), com seus imperativos e suas conseqüências lógicas, se há diversas con-
10. SEDAS NUNES, pp. 37-38.

11. LE GOFF antepóe memória coletiva à ciência histórica produzida na academia.

12. SEDAS NUNES, p. 39.

13. Idem, p. 16.

14. BRAUNSTEIN, pp. 14-15.

15. A Escola dos Annales, fundada por Bloch e Febvre, seria outra vertente da "história cientifica" iniciada com Ranke (Stone, pp. 97. 98 e 100). Segundo Fontana, caracteriza-se pelo esforço de modernização formal da ciência histórica, encobrindo a ausência de um pensamento teórico propriamente dito. Outros traços seriam o ecletismo, a vontade globalizadora, com recurso a elementos de outras disciplinas - sociologia, antropologia, economia (Ob. cit., pp. 203-4, e 169-170).

16. Apud BRAUDEL, "Posiçōes da história em 1950". In Escritos..., p. 34.

17. ApudLE GOFF, História, p. 23.

18. A importância dos diversos ritmos da Historia será retomada adiante.

19. Idem, Escritos..., p. 14. unturas, múltiplas realidades da vida social. ${ }^{20}$

Para o historiador francês, a longa duração seria a linha mais útil para uma observação e reflexão comuns às ciências sociais, as quais não deveriam ocupar-se em tantas discussões sobre suas fronteiras, mas sim em traçar as linhas de uma pesquisa coletiva e de temas que permitam atingir uma convergência. ${ }^{21}$

O estudo da duração sob todas as suas formas permite que a História, dialética da duração, entre movimento e semi-imobilidade, ${ }^{22}$ penetre em todo o social, tendo em vista que tudo é História. ${ }^{23}$ Essa idéia de historicidade do social, legado do historicismo do séc. XIX, ${ }^{24}$ foi outra importante contribuição dos historiadores dos annales, no sentido de ampliação das fronteiras do conhecimento histórico, da noção de fonte histórica e das investigações interdisciplinares. ${ }^{25}$

A idéia de que tudo é História, ao estender os objetos do fazer histórico, constitui um primeiro passo para legitimar a existência de uma História do Direito enquanto disciplina autônoma, que examina uma dentre as inúmeras dimensões do social: a dimensão jurídica. É dela que nos ocuparemos no item que segue.

\section{II - Algumas contribuições da ciência histórica à tarefa do historiador do Direito}

A identidade entre os métodos jurídico e histórico seria um rico ângulo para reflexão sobre a racionalidade ocidental, afirma NERHOT. ${ }^{26}$ Como já referimos no início do item anterior, o paradigma do método jurídico e seu compromisso com a veracidade exclui, em princípio, teorizações sobre a ficção no direito. Há que se atentar, todavia, para a diferença entre a prática dos tribunais, e os métodos nela utilizados, e o método concernente à produção acadêmica do conhecimento jurídico, sujeito a semelhantes preocupações em torno da relação sujeito-objeto na construção do conhecimento.

No entanto, não se pretende aqui realizar um quadro comparativo, tampouco um exame das relações entre as duas disciplinas - o que remeteria à questão da interdisciplinariedade e os riscos da apro-
20. BRAUDEL, O Mediterrâneo e o mundo mediterrânico à época de Filipe II. Vol. II, p. 262.

21. BRAUDEL, "Historia e ciências sociais. A longa duraçăo". In Escritos, pp. 75-77."

22. BRAUDEL, O Mediterrâneo. Vol. II, p. 261.

23. BRAUDEL, "Historia e sociologia". In Escritos, pp. 98-99.

24. Sobre historicismo e sua formaçáo no contexto da Alemanha do séc. XIX, vide J. FONTANTA, ob. cit., pp. 118 e128. A categoria da historicidade do social é de grande importância para a reflexão aqui proposta. LE GOFF, citando P. VEYNE, afirma que a historicidade, incluindo no campo da história novos objetos (o que até então era considerado nonévénémentiel), colaborou para excluir uma idealização da História - já que tudo era Historia (Ob. cit., p. 19).

25. PETERSON, Silvia. O conhecimento histórico..., p. 215.

26. No princípio era o direito..., cit.. A definiçáo de Taine para o método historico teria as seguintes etapas: 1) pesquisa dos fatos, 2) classificação dos fatos em classes; 3) defini-los; 4) estabelecer relaçóes de dependência para verificar em que medida formam sistema com outras definiçбes. Paralelamente, o método jurídico, segundo Maccormick, teria algumas semelhanças: 1) pesquisa dos fatos; 2) interpretaçąo dos fatos (que compreende sua classificaçăo); 3 ) interpretar as regras que se reportam a tais fatos; 4) apreciar as regras em relaçăo ao conjunto/sistema de regras (Ob. cit., pp. 93-94). 
priação indevida de conceitos de uma área por outra. ${ }^{27}$ Busca-se investigar, à luz da historiografia, o estatuto cognitivo da história do direito, seus limites, sua especificidade, o que a torna um ramo da História, alguns elementos de uma possível "teoria da História do Direito". Tais reflexões aparecem usualmente como um pequeno item introdutório às obras de História do Direito, ${ }^{28}$ sem maior aprofundamento, a despeito de constituírem a opção epistemológica (ainda que inconsciente), o modus operandi do trabalho de investigação histórico-jurídica efetuada.

Primeiramente, faz-se mister identificar seu objeto. Para WIEACKER, o objeto da História do Direito seria a compreensão dos "ordenamentos jurídicos passados (ou, eventualmente, vigentes), através da exploração da dimensão histórica do direito". A História do Direito Privado intentada pelo autor "ocupa-se dos pressupostos culturais e científicos do direito privado de hoje". 29

Outros autores, como NUNO ESPINOSA, ${ }^{30}$ indicam como objeto deste

27. PETERSEN, Silvia. Algumas observaçöes sobre a interdisciplinariedade, pp. 109-111. pensamento jurídico contemporâneo, do professor pernambucano Nelson Saldanha. A obra de MIGUEL REALE, Horizontes do Direito e da História, coletânea de artigos diversos, contém alguns textos que abordam o tema. Nos perídicos, encontramos um antigo texto de CABRAL DE MONCADA, historiador português, publicado no Boletim da Faculdade de Direito de Coimbra de 1929, intitulado Problemas metodológicos da história do direito.

29. WIEACKER, pp. 1-3.

30. História do Direito Português, pp. 9 e ss.

31. A palavra aqui designa os fatores que, numa dada sociedade, originam regras de conduta, tais como a lei, o contrato, o costume, os mitos nas sociedades primitivas. Outro sentido para o termo fonte seria aquele utilizado pelos historiadores: os textos jurídicos os mitos nas sociedades primitivas. Outro sentido para o termo fonte seria aquele utilizado pelos historiadores: os textos juridicos
seriam a fonte por excelência, não só para a História do Direito, mas também para a própria ciência histórica e disciplinas afins, consoante o objeto de investigaçăo.

32. ESPINOSA, Nuno. Ob. cit., p. 10.

33. KOSELLECK, Histoire, Droit et Justice, p. 175
28. A única exceção em forma de livro, encontrado na Biblioteca da Faculdade de Direito da UFRGS, é O problema da história no tória événémentielle, busca compreender as "espantosas permanências" que existem no interior das civilizações. ${ }^{34} \mathrm{O}$ Direito move. se predominantemente no ritmo dos trends seculares e das longas flutuações, ${ }^{35}$ e não no tempo ágil das crises econômicas e dos eventos.

Não significa que não possa haver, no percurso histórico-jurídico, o evento, o tempo curto, em especial quando se trata do "jovem" direito constitucional e suas fontes - mais ligado às intempéries políticas (história política é, por excelência, a esfera do tempo événementiel) do que, por exemplo, o direito civil, nascido entre os romanos, contando com longos dois mil anos de trajetória na cultura jurídica ocidental. Contudo, indubitável que o Direito, pela sua própria razão de ser, com sua aspiração à justiça e à segurança nas relações entre as pessoas na sociedade, transcorra sobre a repetibilidade estrutural, e seja espaço privilegiado para as permanências. Não se trata direito, à medida em que se transforma a é reflexo das necessidades econômicas e políticas da conjuntura. É, nas palavras de PAOLO GROSSI, "dimensão da vida" ${ }^{36}$

Por vezes, como a ética e a moral, custa a absorver as modificações, ocorren-

\section{O Mediterrâneo. Vol. II. p.132.}

35. Ldem, pp. 262 e 265. Registra BRAUDEL que "...0s movimentos longos das civilizações, suas florações, no sentido tradicional da palavra, surpreendem-nos e desconcertam-nos" (Ob. cit., p. 268).

36. GROSSI, El punto y la línea (Historia del derecho y derecho positivo en la formación del jurista del nostro tiempo), discurso proferido por ocasião do recebimento do título de doutor honoris causa na Universidade de Sevilha, 1998, p. 21.

37. KOSELLECK, p. 178.

38. Idem, pp. 176-177.

39. SALDANHA, cit., pp. 54-58.

do o fenômeno do "desuso" das regras. Outras vezes, pelo contrário, adianta-se em relação à moral vigente. Porém sua relação com a permanência segue sendo intrínseca: as próprias inovações operadas no plano jurídico só adquirem relevância pela sua capacidade de constituírem-se estruturas repetitíveis. ${ }^{37}$

Atentar para a peculiaridade do ritmo temporal no Direito não interessa somente à leitura da experiência jurídica, mas também aos pesquisadores de outras áreas que manuseiam fontes jurídicas em suas pesquisas - fontes que, além de exigirem hermenêutica própria, uma vez que sua linguagem e conceitos têm significado diverso da linguagem leiga ${ }^{38}$ devem ser vistas com atenção à sua dimensão temporal própria.

Na tentativa de "teorizar" o estudo jurídico-histórico, NELSON SALDANHA esboça alguns elementos e premissas que integrariam o instrumental teórico da disciplina. Refere-se a um sistema de referências que representam um modo de conhecer o direito, distinguindo uma mera investiga sos históricos (pesquisa descritiva) do entendimento da realidade jurídica como fenômeno histórico. ${ }^{39}$ Não seria um mero método de coleta de dados, mas almejaria a compreensão dos processos, sendo o regisde uma esfera de imobilidade total: muda o sociedade, pois é parte integrante do social, ção das realidades jurídicas e seus percur-

Revista da Faculdade de Direito da UFRGS, v. 18, 2000 
tro dos eventos um ponto de partida, e sempre associada à concepção do direito como histórico, em oposição ao direito natural conservador e imutável. Tratando-se do Direito brasileiro, há que se ter em conta a tensão entre o legado europeu e a latência das espontaneidades criadoras, colocando as necessidades jurídicas nacionais em plano de independência, evitando-se a atitude mimetista. ${ }^{40}$

Em sentido semelhante, afirma KOSELLECK que a História do Direito teria como resultado uma linha cronológica (enfrentando, tal como o cientista-historiador, o problema da periodização) ${ }^{41}$ e uma estrutura sistemática. ${ }^{42}$

Revela-se, portanto, ainda incipiente a tarefa de elaboração de um instrumental teórico da História do Direito, muito aquém dos lugares teóricos assinalados por MARX para compreender a realidade histórica. Conta-se apenas com algumas premissas que, contudo, já auxiliam o investigador, e, principalmente, reagem contra a mentalidade vigente, que concebe o direito como a-histórico, dissociado do todo social. A reflexão acerca da necessidade de rompimento com o senso comum (o "direito ofi-

\section{Idem, pp. 99-99.}

41. NUNO ESPINOSA aborda o problema da periodização na História do Direito, ob. cit., pp. 14-15. Nelson Saldanha elogia 0 esforço de juristas como Wieacker, Wolf e Michel Villey, quando propõem novas periodizaçôes para a história do direito, acompanhadas do exercício de repensar as antigas fontes do direito romano, afastando as interpretaçōes liberal-individualistas que caracterizaram a História do Direito até o início deste século (Ob. cit., p. 85).

42. KOSELLECK, p. 173

43. A História contribui, ainda, para oferecer novos código de leitura para o fenômeno juríico: além de ser visto como reação aos problemas sociais, ou como regulador de litígios, pode ser enfocado sob o prisma da contestaçăo da ordem dada, a partir do questionamento acerca de seus mecanismos de elaboraçăo, que refletem a legitimaçäo do poder de certos grupos Nesse questionamento acerca de seus mecanismos de elaboração, que refletem a legitimaçăo do poder de certos grupos. Nesse sentido, e inter.
pp. 23 e 29).

44. SEDAS NUNES, $p .43$

45. Tal qual a incessante reconstrução do passado pelos historiadores, mencionada por LE GOFF (Ob. cit., p. 25).

46. PETERSEN, O conhecimento histórico..., p. 213.

47. WIEACKER, p. 5.

\section{Conclusão}

As breves reflexões aqui expostas sobre a História do Direito foram feitas a partir de contribuições de duas das grandes o marxismo e a escola dos annales, a respeito da necessidade de elaboração de um ins trumental teórico e da relação com o tempo, respectivamente. Trata-se, evidentemente, de possíveis visões sobre a relação entre História e História do Direito, sem a pretensão de exaustividade.

Do ponto de vista da História científica, afigura-se-nos legítima a constituição da História do Direito, como um de seus ramos especializados, dotado de ritmo peculiar e voltado à dimensão jurídica da realidade social (tendo em vista a historicidade do social, que ampliou os objetos "historicizáveis"). ${ }^{49}$

A História do Direito, disciplina autônoma, conta com alguns pressupostos te óricos, algumas categorias que auxiliam o pesquisador na periodização e na construção do conhecimento. Cabe a ele buscar na ciência histórica seu instrumental, mantendo-se atento às discussões que ali desenvolvem-se (sem perder de vista as especificidades de seu objeto). Defendemos, ainda, a importância do papel cultural da História do Direito, essencial para a formação dos juristas de nosso tempo. ${ }^{50}$ escolas da história estrutural ou científica, ${ }^{48}$

O objeto da História do Direito é circunscrito às formas da experiência jurídica dos homens no tempo (o que já não é pouco!). Não se pode, portanto, exigir-lhe explicações globais, tampouco respostas a perguntas equivalentes àquelas formuladas na seara História científica. ${ }^{51}$

Com isso, é válida a lição de KOSELLECK, no sentido de que a História do Direito precisa de outras abordagens historiográficas, não como meras auxiliares na leitura de seus textos, mas para a compreensão de uma História do Direito integral..$^{52}$

Acrescentaríamos que a História do Direito não apenas precisa dos conhecimentos trazidos pelas outras Histórias, enquanto troca interdisciplinar, mas fundamentalmente das contribuições relativas a seu corpo teórico, conceitos e categorias, devendo manter-se atenta aos debates sobre o estatuto epistemológico de sua "ciência-raiz", que é a ciência histórica.

\section{Bibliografia}

BACHELARD, Gaston. A formação do espirito científico. Trad. Estela dos Santos Abreu. Rio de Janeiro: Contraponto, 1996.

BRAUDEL, Fernand. O Mediterrâneo e o Mundo Mediterrânico na Época de Felipe II. Trad. da 4. ed: francesa (1979). São Paulo/Lisboa:

48. Ambas caracterizam-se pela extensão do objeto e modelo científico de conhecimento - princípio macro-explicativo e sistêmico (PETERSEN, ob. cit., p. 215).

49. LE GOFF, cit., p. 19

50. GROSSI, ob. cit., p. 19.

51. Deixamos de lado, por ora, as críticas "pós-modernas" às explicações globais da História, bem como a discussão em torno da "volta à narrativa".

52. KOSELLECK sustenta que os fenômenos de interdependência oferecem interpretaçōes pertinentes, apesar de toda a reserva de revisão (Ob. cit., pp. 179-180). 
Martins Fontes - Publicações D. Quixote, 1984.

Escritos sobre a História. Trad. J. Guinsburg e Tereza Cristina Silveira da Mota. São Paulo: Perspectiva, 1978.

BRAUNSTEIN, NESTOR. "Cómo se constituye una ciencia?". In Psicología: Ideologia y ciencia. México: Siglo XXI, 1979.

CERTEAU, Michel de. La historia, ciencia y ficción. História, México, INAM, nº 16, 1987.

CÉZAR, Temístocles. "Sob o firmamento da História: o 'Mito' do texto como representação objetiva do passado". In FELIX, Loiva, e ELMIR, Cláudio (org.). Mitos e heróis. Porto Alegre: UFRGS, 1998.

FONTANA, Josep. História: análise do passado e projeto social. Trad. Luiz Roncari. São Paulo/Bauru: EDUSC, 1998.

GROSSI, Paolo. El punto y la línea (historia del derecho y derecho positivo en la formación del jurista del nostro tiempo). Discurso proferido por ocasião do recebimento do título de doutor honoris causa na Universidade de Sevilha, 1998.

HOBSBAWN, Eric. "Não basta a história de identidade". In Sobre História. São Paulo: Cia. das Letras, 1998.

KOSELLECK, R. "Histoire, Droit et Justice". In L'expérience de l'histoire. Trad. Alexandre Escudier. Paris, Seuil, Gallimard, HautesÉtudes, 1997.

LACERDA, Sônia. "História, narrativa e imaginação histórica". In SWAIN, Tania. História no plural. Brasília: UnB, 1994.

LE GOFF, Jacques. História e Memória. Trad. Irene Ferreira, Bernardo Leitão, Suzana Ferreira Borges. 4. ed., São Paulo/Campinas: Unicamp, 1996.
NERHOT, Patrick. "No princípio era o Direito...". In Passados recompostos (campos e canteiros da História), org. Boutier, Jean; e Julia, Dominique. Rio de Janeiro: UFRJ, ed. FGV, 1998.

PETERSEN, Silvia Regina Ferraz. "O conhecimento histórico na atualidade". In Rumos da pesquisa, org. Krieger e Aranha. Porto Alegre: Propesq/UFRGS, 1998.

"Algumas observações sobre a interdisciplinariedade". In 50 anos do IFCH/ UFRGS - Publicação comemorativa. Porto Alegre: UFRGS, 1993.

ROUANET, Sérgio. "Razões do neoiluminismo". In A criação histórica. Castoriadis e outros (Seminário organizado pela Secretaria Municipal de Cultura/ PMPA). Porto Alegre: Artes e Ofícios, 1992.

RÜSEN, Jörn. "Narratividade e objetividade nas ciências históricas". Textos de História, vol. 4, nำ 1, 1996.

. "A história entre a modernidade e a pós-modernidade". História: Questões $\mathcal{B}$ Debates. Curitiba, vol. 14 , no $26 / 27$, jan./ dez., 1997.

SALDANHA, Nelson. O problema da história na ciência jurídica contemporânea. 2. ed., Porto Alegre: Coletânea Osvaldo Vergara, 1978.

SEDAS NUNES, A. Conhecimento nas ciências sociais. Lisboa: Instituto Ciências Soc. Univ. Lisboa, s/d.

SILVA, Nuno Espinosa Gomes da. História do Direito Português. Lisboa: Fundação Calouste Gulbekian, 1985.

STONE, Lawrence. "El resurgimiento de la narrativa. Reflexiones acerca de una nueva y vieja historia." In El pasado y el presente. México, FCE, 1986.

WIEACKER, Franz. História do Direito Privado Moderno. Trad. A. M. Botelho Hespanha. 2. ed., Lisboa: Fund. Calouste Gulbekian, 1993.

\section{O Sistema Constitucional Brasileiro e as Recentes Inovações no Controle de Constitucionalidade (Leis $\mathrm{n}^{\circ} \mathbf{9 . 8 6 8 \text { , }}$ de 10 de novembro e $n^{\circ}$ 9.982, de 03 de dezembro de 1999)}

\section{Ellanoel Eançalves OFenxeina OFitho}

Professor Titular de Direito Constitucional da Faculdade de Direito da USP. Doutor honoris causa da Universidade de Lisboa. Doutor pela Universidade de Paris. Ex-Professor visitante da Faculdade de Direito de Aix-en-Provence (França). Membro da Comissão Executiva da Association

Internationale de Droit Constitutionnel - AIDC. Presidente do Instituto "Pimenta Bueno" Associação Brasileira dos Constitucionalistas.

\section{I - Introdução}

16

O complexo sistema de controle de constitucionalidade que prevê a Constituição vigente sofreu há pouco o impacto de duas leis que vieram regular, uma, o processo e o julgamento, perante o Supremo Tribunal Federal, da ação direta de inconstitucionalidade e da ação direta de constitucionalidade, outra, a argüição de descumprimento de preceito fundamental da Constituição. São elas as Leis no 9.868 , de 10 de novembro e $\mathrm{n}^{\mathrm{O}}$ 9.982, de 03 de dezembro de 1999.

2. A importância de tais leis avulta porque tocam no subsistema da Constituição que garante todos os demais, qual seja o de controle da constitucionalidade dos atos ou omissões dos Poderes constituídos. Realmente, este é a condição da supremidade da norma constitucional, portanto, da valia (político-jurídica) da própria Lei Fundamental.

Com efeito, tocam elas em aspectos fundamentais desse controle. Refletem mudanças quanto ao significado desse próprio controle no sistema constitucional, e, portanto, o papel ou função do Supremo Tribunal Federal, enquanto guarda da Constituição. Mais ainda, importam em modificação na maneira de conceber o efeito da desconstituição do ato inconstitucional, o que revoluciona concepção tradicionalmente assente na doutrina e na jurisprudência brasileiras sobre a natureza de tal ato. 